\title{
Evidencia de Deducciones Erróneas y sus Posibles Efectos en el Aprendizaje Inicial del Concepto de Célula en la Escuela Primaria
}

\section{Evidence of Erroneous Deductions and their Possible Effects on the Initial Learning of the Concept of Cell in Primary School}

\author{
Valeria Carolina Edelsztein ${ }^{1}$ \\ Lydia Raquel Galagovsky² \\ ${ }^{1}$ Consejo Nacional de Investigaciones Científicas y Técnicas (CONICET), Buenos Aires, Argentina. \\ Autora correspondiente: valeriae@conicet.gov.ar \\ ${ }^{2}$ Universidad de Buenos Aires (UBA), Facultad de Ciencias Exactas y Naturales, Buenos Aires, Argentina.
}

Resumen: En este trabajo se han obtenido evidencias sobre dificultades para procesar información referida al concepto de célula en estudiantes de escuela primaria. Se identificaron posibles deducciones erróneas que podrían establecer estudiantes de $5^{\text {to }}$ grado (10-11 años) que intentaran procesar cognitivamente, y por primera vez, la información de libros de texto escolares y del discurso docente sobre el tema y se diseñó un cuestionario con el objetivo de hallar evidencia de estas deducciones. Fue posible detectar algunas evidencias de construcción de modelos explicativos incipientes siendo destacable la aparición de modelos consistentes, pero científicamente incorrectos. Luego, se aplicó el mismo cuestionario a estudiantes de $6^{\text {to }}$ y $7^{\text {mo }}$ grado (11-13 años) y se observó que algunos patrones de respuesta se mantenían e, incluso, se afianzaban. Estos modelos podrían dar cuenta del origen de errores o dificultades en la comprensión del concepto célula en estudiantes de niveles educativos subsiguientes.

Palabras clave: Escuela primaria; Célula; Aprendizaje; Libro de texto; Discurso docente.

\begin{abstract}
In this paper we have obtained some evidence on difficulties in processing information about the cell among primary school students. We identified possible misleading deductions that $5^{\text {th }}$ grade students (10-11 years) could establish when trying, for the first time, to cognitively process information on the subject from school textbooks and teacher discourse, and we designed a questionnaire to find evidence of these deductions. It was possible to detect some evidence of incipient explanatory models. It is important to highlight the emergence of consistent but scientifically incorrect models. Then, the same questionnaire was applied to $6^{\text {th }}$ and $7^{\text {th }}$ grade students (11-13 years), and it was found that some response patterns prevailed and were even reinforced. These models could account for the origin of errors or difficulties in understanding the concept of cell among students of subsequent educational levels.
\end{abstract}

Keywords: Primary school; Cell; Learning; School textbook; Teacher discourse.

Recebido em: 28/06/2019

Aprovado em: 19/11/2019 


\section{Introducción}

En biología, el concepto de célula es fundamental para la comprensión del concepto de ser vivo y para entender el funcionamiento de los organismos complejos como resultado de la labor celular coordinada. Sin embargo, las investigaciones sobre las representaciones del alumnado de escuela secundaria y primeros años de universidad muestran que su aprendizaje presenta numerosas deficiencias, pese a los esfuerzos docentes (BANET; AYUSO, 2000; BUITRAGO REINOSA, 2014; FLORES; TOVAR; GALLEGOS, 2003; LEGEY et al., 2012; MENGASCINI, 2005, 2017; OSPINA QUINTERO; GALAGOVSKY, 2017; RODRÍGUEZ PALMERO, 2000; RIEMEIER; GROPENGIEßER, 2008). Rodríguez Palmero (2000), tras una extensa revisión bibliográfica, encontró que un $70 \%$ de los trabajos analizados identificaron fallas de comprensión sobre el concepto célula. Las dificultades de los alumnos se relacionaron, principalmente, con su composición físico-química y funcionamiento, con el concepto de célula viva y se detectaron problemas de apreciación de las dimensiones celulares. Por ejemplo, si bien reconocen la composición celular en términos descriptivos y asumen que la célula realiza funciones vitales, no vinculan el crecimiento con la reproducción de células.

Sin embargo, pese a que la comprensión de la estructura y funcionamiento de la célula se ha detectado como obstáculo, existen muy pocas investigaciones acerca de las representaciones que poseen y los modelos explicativos que construyen sobre la célula los alumnos de escuela primaria (MACNAB; HANSELL; JOHNSTONE, 1991; MALDONADO GALDEANO; ROSSETTO, 2009). Esto es particularmente llamativo dado que es, en este ciclo, cuando se enseña dicho concepto por primera vez.

Por otra parte, los textos escolares son el material didáctico más empleado por docentes, tanto de primaria como de secundaria, como guía y apoyo de la enseñanza (MARTÍNEZ LOSADA; GARCÍA BARROS, 2003) y sus propuestas ejercen una influencia notable en la selección de contenidos, su abordaje y el consecuente aprendizaje de los estudiantes (BARROW, 2000; CARVALHO et al., 2011; GARCÍA BARROS; MARTÍNEZ LOSADA, 2005; JIMÉNEZ; PERALES, 2002; LÓPEZ-MANJÓN; POSTIGO, 2009, 2014; MATUS; BENARROCH; PERALES, 2008; OTERO; MOREIRA; GRECA, 2002; PERALES; JIMÉNEZ, 2002; PÉREZ CEBALLOS et al., 1999; PÉREZ DE EULATE; LLORENTE; ANDRIEU, 1999). En este sentido, Angulo Pinedo $(1999,2000)$ expresa que los libros de texto han ejercido una profunda influencia negativa en la comprensión biológica de la funcionalidad y dinámica de la célula al representarla de manera estática y simplificada tanto en textos universitarios como de enseñanza secundaria. En concordancia, Camacho Gonzáles et al. (2012) han observado que las representaciones de los estudiantes están altamente influenciadas por las imágenes de los libros de texto. Flores, Tovar y Gallegos (2003) hallaron que el $43 \%$ de los alumnos de escuela secundaria creía que las células animales son generalmente redondas, y Buitrago Reinosa (2014) identificó que alumnos de primeros años de secundario concebían a la célula con una imagen de "huevo frito, plano y estático".

En investigaciones previas acerca de los sistemas del cuerpo humano en nivel de escuela primaria, reflexionamos acerca de cómo la información excesivamente fragmentada y sobre-simplificada en los textos escolares y el discurso docente puede conducir a conceptos erróneos en el aprendizaje (EDELSZTEIN; GALAGOVSKY, 2017; GALAGOVSKY; EDELSZTEIN, 2018). En este trabajo, presentamos una indagación acerca de las posibles deducciones 
erróneas sobre el concepto de célula que podría establecer un grupo de estudiantes de $5^{\text {to }}$ grado de escuela primaria (10-11 años) que se acerca al tema por primera vez, a partir del discurso docente y del material de los libros de texto. Se implementó un cuestionario diseñado ad hoc con el fin de hallar evidencia de estas posibles DE. Además, a partir de las respuestas a este cuestionario y a la evaluación formal tomada por la docente, fue posible detectar algunas evidencias de construcción de modelos explicativos incipientes acerca de la célula. También se analizó si estos patrones de respuestas podrían afianzarse o no en estudiantes de $6^{\text {to }}$ y $7^{\text {mo }}$ grado (11-13 años), constituyéndose en futuros obstáculos para el aprendizaje en años subsiguientes.

\section{Marco Teórico}

Este trabajo se basa en la propuesta teórica de que la existencia de problemas comunicacionales en el aula puede ser el origen de la construcción de aprendizajes erróneos y modelos explicativos científicamente incorrectos por parte de los estudiantes novatos (GALAGOVSKY; BEKERMAN, 2009) y toma en cuenta las siguientes consideraciones:

1. Que el discurso de cada ciencia está constituido por un conjunto de lenguajes expertos y es factible reconocer posibles obstáculos lingüísticos variados dentro de cada ciencia específica (BEKERMAN, 2007; BEKERMAN; GALAGOVSKY, 2009; GALAGOVSKY; BEKERMAN, 2009; GALAGOVSKY; DI GIACOMO; CASTELO, 2009; GARÓFALO, 2010; GARÓFALO; ALONSO; GALAGOVSKY, 2014; GARÓFALO; GALAGOVSKY; ALONSO, 2015). Es decir, la información que se presenta a los estudiantes está expresada en múltiples lenguajes y eso acrecienta la posibilidad de cometer errores por generalización o transposición de códigos entre lenguajes;

2. Que la información de los libros de texto y el discurso docente puede originar deducciones erróneas (DE) en los estudiantes y que, a su vez, estos errores se constituyen en las evidencias sobre las cuales se pueden deducir procesos cognitivos involucrados en el aprendizaje (EDELSZTEIN; GALAGOVSKY, 2017);

3. Que la combinación de dichos procesos cognitivos daría cuenta de la generación de obstáculos de aprendizaje. Esto implica que los obstáculos pueden provenir de ideas previas, pero también de ideas que se generarían durante los procesos cognitivos involucrados durante el aprendizaje inicial.

Teniendo en cuenta estas consideraciones, el presente trabajo se orientó hacia la identificación de posibles deducciones erróneas (DE) que podría establecer un grupo de estudiantes novatos de $5^{\text {to }}$ grado que intentaran procesar cognitivamente las figuras $y$ explicaciones de un libro de texto escolar y la información proporcionada por el discurso docente sobre el tema célula. Se diseñó un cuestionario con el objetivo de hallar evidencia de estas posibles DE y, luego, se aplicó este cuestionario a estudiantes de sexto y séptimo grado de la misma escuela. Se presentarán los datos y la discusión teniendo en cuenta:

- la correlación entre las posibles DE y las respuestas de los estudiantes a nivel grupal. De esta manera, se buscará reflexionar acerca de cómo la forma de presentar los contenidos y los materiales seleccionados podrían originar obstáculos en el aprendizaje inicial de la célula; 
- el análisis de las respuestas individuales de cada estudiante, con el fin de estudiar inconsistencias internas o evidenciar la construcción de incipientes modelos explicativos.

\section{Metodología}

La investigación involucró la observación de clases durante la enseñanza del tema célula en un grupo mixto de 15 estudiantes de $5^{\text {to }}$ grado (10-11 años) en una escuela primaria pública de gestión privada de la Ciudad de Buenos Aires con población de sustrato socioeconómico medio. Fueron 5 clases de 120 minutos cada una. A lo largo de las clases, la docente presentó el tema, se observaron videos, se miraron imágenes en computadora y se trabajó con textos provenientes de manuales escolares y explicaciones por parte de la docente para diferenciar células procariotas y eucariotas $y$, dentro de las eucariotas, células animales y vegetales. Al finalizar la última clase, la docente tomó una evaluación. Algunas de las preguntas y sus resultados se muestran en las Tablas 1 y 2.

Un mes después de la última clase, se aplicó individualmente a los 15 estudiantes un cuestionario diseñado ad hoc que constaba de una pregunta de elección múltiple sobre la que debían marcar todas las opciones que creyeran correctas (Tablas 3). La toma del cuestionario demandó 20 minutos. Además, se aplicó este cuestionario sobre una población de alumnos de $6^{\text {to }}$ y $7^{\text {mo }}$ grado de la misma escuela, que habían sido enseñados en años anteriores sobre estos temas por otras docentes y con diferentes textos escolares. Los resultados se muestran en las Tablas 3 y 4.

De esta forma, la investigación involucró cuatro fases:

- Fase I: registro de observaciones de clases para identificar posibles DE por parte de los estudiantes a partir del discurso docente y el material de textos escolares;

- Fase II: diseño de un cuestionario ad hoc que permitiera hallar evidencias sobre estas DE y revelara posibles obstáculos en el procesamiento de la información durante el discurso de enseñanza;

- Fase III: comparación de los resultados de la aplicación del cuestionario ad hoc a los estudiantes de quinto grado con respecto de los obtenidos en la evaluación formal final tomada por la docente y con respecto a las DE propuestas. Análisis del desempeño grupal e individual;

- Fase IV: comparación de los resultados obtenidos con el cuestionario ad hoc entre los estudiantes de quinto, sexto y séptimo grado.

\section{Materiales Impresos Utilizados en las Clases}

Los textos y las imágenes con las que trabajaron los alumnos de $5^{\text {to }}$ grado durante las clases se muestran a continuación. Se trata de fragmentos del material bibliográfico impreso preparado por la docente con recortes de diferentes textos escolares, que abarcan específicamente el tema de célula y de organismos unicelulares y pluricelulares.

La Figura 1 muestra las imágenes de células procariotas y eucariotas y de células vegetales y animales que contenía el material. Se observa que refieren a la típica estandarización del modelo de célula, están cargadas de convenciones de escala y forma que en los textos nunca se explicitan. 
Figura 1 - Imágenes de células procariotas y eucariotas y de células vegetales y animales del material impreso que la docente le estregó a los estudiantes de quinto grado

(a)

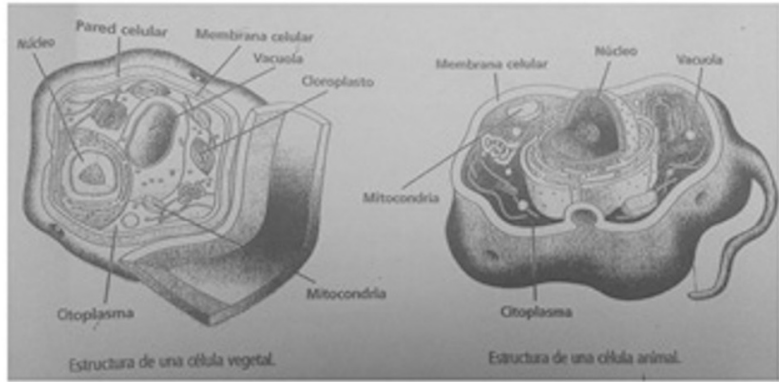

(b)

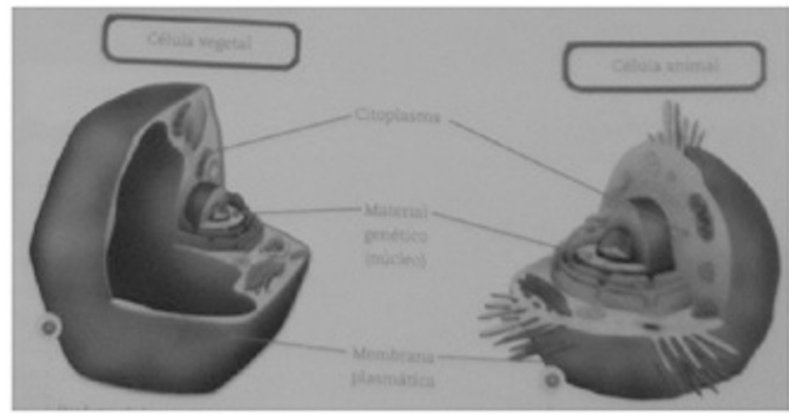

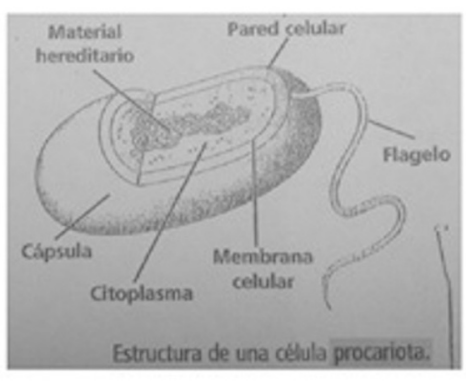

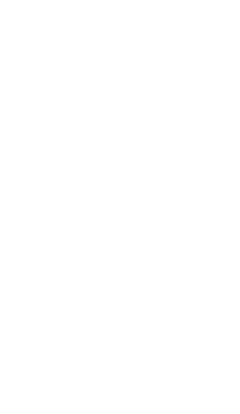

Fuente: material impreso preparado por la docente.

\section{Los textos del material impreso se transcriben a continuación:}

\section{Si está vivo, tiene células (Texto 1)}

Todos los seres vivos están formados por células. La unidad vital más pequeña es la célula. Las células realizan todas las funciones que caracterizan a los seres vivos: se alimentan, se relacionan con el medio y se reproducen.

Algunos organismos son unicelulares, es decir, están formados por una única célula. Otros, en cambio, son pluricelulares, ya que están formados por muchas células.

Las células y los organismos (Texto 2)
Cada organismo unicelular es una única célula. Los organismos multicelulares están formados por células
diferentes y, muchas de ellas, se especializan y realizan funciones vitales distintas. Los grupos de células de un
organismo multicelular que realizan una misma función conforman un tejido. A su vez, diferentes tejidos que
cumplen funciones similares forman un órgano; y distintos órganos forman lo que se llama sistema de órganos.
Un organismo se compone de distintos sistemas.
Las células de la mayoría de los seres vivos tienen un compartimiento interno, el núcleo, que contiene
los materiales que participan en la reproducción de la célula. Estas células se llaman eucariotas. En algunos seres
vivos unicelulares, como las bacterias, las células no tienen núcleo y se llaman procariotas.

\section{Las células por dentro (Texto 3)}

Todas las células están rodeadas de una membrana celular o membrana plasmática que permite la entrada de oxígeno, agua y nutrientes, y la salida de dióxido de carbono y otras sustancias de desecho. Hacia el interior, se halla el citoplasma, un material gelatinoso formado, en gran parte, por agua.

\section{Los antibióticos (Texto 4)}

Hace unos cien años, no existían tratamientos efectivos contra muchas de las enfermedades provocadas por microorganismos. Esta situación cambió totalmente con el descubrimiento de los antibióticos. Uno de los avances más importantes se produjo en 1928. Ese año, el científico Alexander Fleming, mientras estudiaba algunos cultivos de bacterias, observó que en uno de ellos había crecido un moho. Con el transcurso de los días, notó que, a medida que los mohos crecían, las bacterias desaparecían. Concluyó, entonces, que los mohos mataban bacterias. Al investigar de qué tipo de moho se trataba, se dio cuenta de que era el Penicillium notatum, un moho que crece habitualmente sobre el pan. Once años más tarde, los científicos Howard Florey y Ernst Chain aplicaron el descubrimiento que había realizado Fleming y lograron aislar la sustancia producida por el hongo que se llamó penicilina. A partir de ese momento, comenzó a ser utilizada para el tratamiento de diversas enfermedades. 


\section{Identificación de posibles deducciones erróneas (DE) por parte de los estudiantes a partir del discurso docente y el material de texto}

Es habitual que, en grados superiores de escuela primaria o en la escuela secundaria, los docentes exploren las ideas previas de los estudiantes sobre la célula antes de dar comienzo a la enseñanza. Sin embargo, es en $5^{\text {to }}$ grado cuando se menciona por primera vez este concepto. Por tal motivo, la maestra presentó directamente el tema y fue introduciendo preguntas que hicieron surgir explícitamente ideas o razonamientos de los estudiantes acerca de la célula. Luego, trabajó con videos y lecturas en clase con información proveniente de distintos libros de texto escolares.

\section{Diálogos entre la docente y los estudiantes}

Se plasman en este punto cinco relatos breves (a)-(e), a modo de ejemplo, en los que se identifica a la docente con la letra $D$, y a diferentes alumnos con la letra $A$ :

a. Luego de definir reiteradamente "la célula como la mínima unidad de vida", la docente ratificó que todos los seres vivos están formados por células. Dos alumnos comentaron sin obtener respuestas:

A: Entonces... si todos los seres vivos tienen células, ¿las células están vivas? Porque... ino tienen células adentro!...

A: ¡No todos los seres vivos tienen células!... Porque las células están vivas y no tienen células.

b. En otra oportunidad se produjo el siguiente intercambio:

D: La unidad vital más pequeña es la célula. ¿Qué significa esto?

A: Que es la más chica.

A: Que la necesitamos para vivir.

A: Que es una cosa muy importante para la vida.

A: Que está viva.

A: Que no tiene células adentro de la célula.

D: Que no tiene células adentro, que ella misma es esa unidad. Lo que está adentro de las células ¿podría existir solo y tener vida? No. Tiene que estar todo este conjunto para que pueda tenervida.

A: Pero, entonces, ¿de qué están hechas las células de las células?

Estos intercambios (a) y (b) ponen en evidencia que, mientras el énfasis del discurso docente estuvo puesto en el tamaño y la importancia de las células para la vida, las preguntas de los niños ponían de manifiesto cuestiones conceptualmente más profundas, por ejemplo la duda de cómo la célula puede estar viva si adentro no tiene vida. Es decir, ellos se cuestionaron sobre el significado de "unidad vital" y sus funciones.

c. Frente al título del Texto 1, "Si está vivo, tiene células", la docente indagó:

D: ¿Están de acuerdo con el título? ¿Hay algo que puede ser que no esté vivo pero que tenga células?

A: Sí, puede haber. Animales muertos, plantas...

A: No. Si está vivo tiene células, entonces si tiene células está vivo.

D: ¿Siguen habiendo células en los que se murieron? ¡Sí! Pero no están vivas. 
La docente misma dio la respuesta y con eso terminó la discusión. Sin embargo, los estudiantes se quedaron con dudas al respecto que expresaron murmurando entre ellos en voz baja. En particular, no les resultó convincente la idea de que las células muertas siguen siendo células e insistieron con que "si está vivo tiene células" era equivalente a "si tiene células está vivo". Cabe reflexionar, en este punto, que el concepto de célula permanece como tal, aún si sus funciones vitales ya hubieran fenecido y que pueden existir células vivas, aún si el organismo al que pertenecen ya no viviera.

d. La docente explicó las diferencias entre células procariotas y eucariotas y, entre todos, leyeron el Texto 4. La docente señaló que los antibióticos sólo atacan a las células procariotas. Al discutir las estructuras subcelulares, la maestra hizo hincapié en "el núcleo como una parte que contiene información muy importante para cualquier ser vivo", sin distinguir explícitamente el caso de las células procariotas. El siguiente registro da cuenta de ello:

D: Cuando miraron las imágenes al microscopio en las computadoras, vieron que había células en la hoja de la cebolla, una al lado de otra y tenían como un puntito. Ese puntito es el núcleo y contiene una información muy pero muy importante para cualquier ser vivo porque permite que se copien sus características para que se reproduzcan de la misma forma. Tenemos entonces palabras nuevas: citoplasma, núcleo y el material hereditario que también se llama ADN. Si yo les pregunto ¿este ADN en qué parte de la célula de la cebolla está?

A: En el núcleo.

D: Bien. El núcleo es una parte importante de la célula justamente porque contiene el $A D N$.

En este discurso la maestra remite a clases previas, pero no retoma el concepto diferencial de células procariotas y eucariotas. La significación de tener información genética en forma de ADN como requisito para la replicación de la vida pareció quedar oculto bajo el hincapié sobre su localización nuclear sólo en una célula eucariota.

e. Pese a haber dicho anteriormente que existen células procariotas y eucariotas, la docente retoma el tema y habla de "los dos tipos de células" pero, esta vez, refiriéndose a células vegetales y animales. En particular, utilizaron las imágenes de la Figura 1.

D: Les voy a dar unos esquemas de los dos tipos de células: la vegetal y la célula animal. ¿Se acuerdan que hablamos del núcleo, de la pared celular, del citoplasma? Acá hay más organelas, eso que está adentro de la célula. ¿Qué diferencias hay entre estas dos células? A: A mí me parece que la célula vegetal tiene como un vacío y que la célula animal no tiene ninguno.

A: Ésta [la célula vegetal] está medio hueca.

En este diálogo es notorio cómo los estudiantes interpretaron erróneamente que las células vegetales están "vacías" mientras que las animales están "rellenas" (a partir de la Figura 1b). La docente propuso un "juego de las diferencias" para recalcar qué estructuras estaban presentes en unas y ausentes en otras (vacuola, cloroplasto y pared celular) a partir de la Figura 1a pero no profundizó en estas diferencias ni en las funciones de cada una de estas estructuras. 


\section{Posibles DE a partir de los diálogos entre la docente y los estudiantes}

A partir de las imágenes y los textos trabajados y de los fragmentos del discurso docente y las subsecuentes interacciones con los estudiantes, algunas de las posibles DE que podrían hacer los alumnos y que darían cuenta de posibles problemas de comunicación serían:

1. Todas las células tienen forma similar (Figura 1).

2. Algunas células (pero no todas) tienen "prolongaciones" hacia afuera y se podrían "tocar" unas con otras. Esas células podrían formar tejidos (Figura 1).

3. Algunas células animales y las procariotas tienen "colitas" (Figura 1a).

4. Las células vegetales son "huecas" y las animales están "rellenas" (Figura 1b).

5. Si todo lo que está vivo tiene células y las células están vivas, entonces están formadas por células también (Texto 1 , relatos $a$ y $b$ ).

6. Las células siempre están vivas (relato $c$ ).

7. Todas las células tienen núcleo porque es el que contiene el ADN, "una parte importante de la célula" (relato $d$ ).

8. Si todas las células siempre están vivas y todas las células tienen núcleo, entonces las células están vivas si tienen núcleo (relatos c y $d$ ).

9. Los tipos "posibles" de células son vegetales y animales; por lo tanto, los hongos y bacterias no están formados por células (relato $e$ ).

10. Si los organismos están formados por sistemas de órganos y los microorganismos son organismos pequeños, entonces deben estar formados de la misma manera (Texto 2).

11. Todos los microorganismos producen enfermedades (Texto 4).

12. Los mohos matan bacterias (Texto 4).

13. Los antibióticos atacan a todos los microorganismos y, si los microorganismos están formados por células, entonces los antibióticos atacan a todas las células (Texto 4).

\section{Resultados de la evaluación formal y de la implementación del cuestionario diseñado ad hoc}

Concluida la fase de observación de las cinco clases en que se enseñó el tema, se indagó sobre cómo habrían procesado cognitivamente los niños la información recibida, intentando detectar evidencias sobre las posibles deducciones erróneas postuladas en la Fase I.

Por un lado, se recabaron los resultados de la evaluación formal tomada por la maestra que consistía, entre otras consignas, en identificar oraciones verdaderas, dentro de una serie de ocho frases que incluía algunas falsas. Las oraciones verdaderas estaban tomadas casi textuales de los textos del material que se había usado durante las clases. La Tabla 1 resume el porcentaje de elección de respuestas de los alumnos de $5^{\text {to }}$ grado, frente a todas las frases (no listadas en el orden en el que se tomaron en la evaluación) y en la Tabla 2 se indica el patrón completo de respuestas individuales para cada uno de los 15 estudiantes de $5^{\text {to }}$ grado durante la evaluación final. 
Tabla 1 - Porcentaje de elección de cada respuesta por parte de los estudiantes de $5^{\text {to }}$ grado, durante la evaluación formal final, luego de la enseñanza del concepto de célula [las frases verdaderas se indican en bastardillas]

\begin{tabular}{|l|c|}
\hline \multicolumn{1}{|c|}{ Consigna: Identifica cuáles de las siguientes oraciones son verdaderas } & \% de elección \\
\hline (a) Todos los seres vivos están formados por células. & 87 \\
\hline (b) Las células de muchos seres vivos tienen núcleo y se llaman eucariotas. & 73 \\
\hline (c) Las células son la mínima unidad de la vida. & 93 \\
\hline (d) Los grupos de células que realizan una misma función forman un tejido. & 87 \\
\hline (e) Todas las células poseen una membrana plasmática. & 80 \\
\hline (f) Alexander Fleming descubrió las bacterias. & 13 \\
\hline (g) La mayoría de las células pueden verse a simple vista. & 7 \\
\hline (h) Los organismos unicelulares están formados por muchas células. & 13 \\
\hline
\end{tabular}

Fuente: elaboración de las autoras.

Tabla 2 - Respuestas de alumnos de $5^{\text {to }}$ grado (1-15) a la evaluación formal de la docente [las respuestas correctas se indican en bastardillas]

\begin{tabular}{|c|c|c|c|c|c|c|c|c|c|c|c|c|c|c|c|}
\hline Opción & 1 & 2 & 3 & 4 & 5 & 6 & 7 & 8 & 9 & 10 & 11 & 12 & 13 & 14 & 15 \\
\hline $\boldsymbol{a}$ & & & & & & & & & & & & & & & \\
\hline $\boldsymbol{b}$ & & & & & & & & & & & & & & \\
\hline $\boldsymbol{c}$ & & & & & & & & & & & & & \\
\hline $\boldsymbol{d}$ & & & & & & & & & & & & & \\
\hline e & & & & & & & & & & & & & & \\
\hline $\mathrm{f}$ & & & & & & & & & & & & & & & \\
\hline $\mathrm{g}$ & & & & & & & & & & & & & & & \\
\hline $\mathrm{h}$ & & & & & & & & & & & & & & & \\
\hline
\end{tabular}

Fuente: elaboración de las autoras.

Con el fin de detectar posibles deducciones erróneas, significaciones y modelos explicativos construidos por los niños, se construyó como dispositivo de indagación sobre aprendizajes el cuestionario ad hoc que se muestra en la Tabla 3. Este instrumento fue aplicado un mes después de la última clase. Su estructura consistía en el disparador Las células... y, a continuación, doce opciones de respuestas para completar la oración (columna izquierda de la Tabla 3, opciones a-l). Los estudiantes debían marcar todas las opciones que les parecieran correctas. En la columna derecha se indican los porcentajes de elección totales sobre los 15 alumnos interrogados. La suma de porcentajes supera el 100\% porque era posible seleccionar más de una opción. La utilización de porcentajes es a fines exclusivamente comparativos, ya que los valores no pretenden ser importantes en sí mismos ni generalizables a otras poblaciones, sino que permiten ser utilizados como evidencias para analizar las deducciones erróneas llevadas a cabo por los estudiantes. En la Tabla 4 se indica el patrón completo de respuestas para los 15 estudiantes de $5^{\text {to }}$ grado durante la implementación del cuestionario ad hoc.

La numeración de los alumnos no es aleatoria sino que funciona a modo de identificación para la comparación, de manera que el alumno 1 de la Tabla 2 se corresponde con el alumno 1 de la Tabla 4 y así sucesivamente.

Las opciones indicadas en bastardillas $(b, g, h, i, j)$ son las únicas científicamente correctas. Dentro de ellas, la opción b había sido un latiguillo ampliamente repetido por la docente durante las clases y en el libro de texto. Las opciones $g, h, i, j$ estaban incluidas, con otra paráfrasis, en los textos leídos en clase y habían sido discutidos por la docente. Las restantes opciones $(a, c, d, e, f, k, l)$ se plantearon a partir de las posibles deducciones erróneas que podrían haber realizado los estudiantes a partir del discurso docente y los textos escolares. 
Tabla 3 - Porcentajes totales obtenidos como respuestas de los estudiantes de $5^{\text {to }}$ grado al cuestionario ad hoc [en bastardillas se indican las respuestas correctas desde el punto de vista científico]

\begin{tabular}{|l|l|}
\hline Las células... & $\%$ \\
\hline (a) están vivas si tienen adentro otras células vivas.. & 20 \\
\hline (b) son lo más pequeño que existe con vida. & 33 \\
\hline (c) están vivas si tienen núcleo. & 67 \\
\hline (d) siempre están vivas. & 13 \\
\hline (e) son destruidas por medicamentos antibióticos. & 40 \\
\hline (f) pueden estar formadas por otras células. & 67 \\
\hline (g) siempre tienen uma membrana que las rodea. & 53 \\
\hline (h) pueden formar los tejidos de un organismo. & 60 \\
\hline (i) forman parte de los animales y plantas. & 27 \\
\hline (j) pueden ser hongos. & 27 \\
\hline (k) todas tienen la misma forma. & 20 \\
\hline (l) todas tienen núcleo. & 73 \\
\hline
\end{tabular}

Fuente: elaboración de las autoras.

Tabla 4 - Respuestas completas de alumnos de $5^{\text {to }}$ grado (1-15) al cuestionario ad hoc [las respuestas correctas se indican en bastardillas]

\begin{tabular}{|c|c|c|c|c|c|c|c|c|c|c|c|c|c|c|c|}
\hline Opción & $\mathbf{1}$ & $\mathbf{2}$ & $\mathbf{3}$ & $\mathbf{4}$ & $\mathbf{5}$ & $\mathbf{6}$ & $\mathbf{7}$ & $\mathbf{8}$ & $\mathbf{9}$ & $\mathbf{1 0}$ & $\mathbf{1 1}$ & $\mathbf{1 2}$ & $\mathbf{1 3}$ & $\mathbf{1 4}$ & $\mathbf{1 5}$ \\
\hline $\mathrm{a}$ & & & & & & & & & & & & & & & \\
\hline $\boldsymbol{b}$ & & & & & & & & & & & & & & & \\
\hline $\mathrm{c}$ & & & & & & & & & & & & & \\
\hline $\mathrm{d}$ & & & & & & & & & & & & & & & \\
\hline $\mathrm{e}$ & & & & & & & & & & & & & & \\
\hline $\mathrm{f}$ & & & & & & & & & & & & & & \\
\hline $\boldsymbol{g}$ & & & & & & & & & & & & & & \\
\hline $\boldsymbol{h}$ & & & & & & & & & & & & & & \\
\hline $\boldsymbol{i}$ & & & & & & & & & & & & & & \\
\hline $\boldsymbol{j}$ & & & & & & & & & & & & & & \\
\hline $\mathrm{k}$ & & & & & & & & & & & & & & \\
\hline I & & & & & & & & & & & & & \\
\hline
\end{tabular}

Fuente: elaboración de las autoras.

\section{Análisis de Resultados y Discusión}

A continuación, se analizarán las respuestas de los estudiantes, tanto a nivel grupal como individual.

\section{Análisis del desempeño grupal}

Para el análisis del desempeño grupal, se clasificarán las opciones de la evaluación y del cuestionario ad hoc en tres categorías que presentan correlaciones entre las respuestas recurrentes de los estudiantes y algunas de las DE propuestas como posibles derivaciones provenientes del procesamiento de la información proporcionada por los textos escolares y el discurso docente (Tabla 5). 
Tabla 5 - Categorización de las opciones de respuesta en la evaluación y en el instrumento ad hoc en relación con las posibles $\mathrm{DE}$

\begin{tabular}{|c|c|c|c|}
\hline Categoría & Tabla 1, opción & Tabla 3, opción & Posibles deducciones erróneas \\
\hline $\begin{array}{l}\text { La estructura de las } \\
\text { células }\end{array}$ & $b, e, g$ & $c, e, g, k, l$ & $\begin{array}{l}\text { - Todas las células tienen forma similar. (DE1). } \\
\text { - Algunas células (pero no todas) tienen "prolongaciones" hacia afuera y se } \\
\text { podrían "tocar" unas con otras. Esas células podrían formar tejidos. (DE2). } \\
\text { - Algunas células animales y las procariotas tienen "colitas". (DE3). } \\
\text { - Las células vegetales son "huecas" y las animales están "rellenas". (DE4). } \\
\text { - Todas las células tienen núcleo porque es el que contiene el ADN, "una } \\
\text { parte importante de la célula". (DE7). } \\
\text { - Los antibióticos atacan a todos los microorganismos y, si los } \\
\text { microorganismos están formados por células, entonces los antibióticos } \\
\text { atacan a todas las células. (DE13). }\end{array}$ \\
\hline $\begin{array}{l}\text { Las células como míni- } \\
\text { mas unidades vitales }\end{array}$ & c & $a, b, d, f$ & $\begin{array}{l}\text { - Si todo lo que está vivo tiene células y las células están vivas, entonces } \\
\text { están formadas por células también. (DE5). } \\
\text { - Las células siempre están vivas. (DE6). } \\
\text { - Si todas las células siempre están vivas y todas las células tienen núcleo, } \\
\text { entonces las células están vivas si tienen núcleo. (DE8). }\end{array}$ \\
\hline $\begin{array}{l}\text { Las células como cons- } \\
\text { tituyentes de los seres } \\
\text { vivos }\end{array}$ & $a, d, h$ & $h, i, j$ & $\begin{array}{l}\text { - Algunas células (pero no todas) tienen "prolongaciones" hacia afuera y se } \\
\text { podrían "tocar" unas con otras. Esas células podrían formar tejidos. (DE2). } \\
\text { - Los tipos "posibles" de células son vegetales y animales; por lo tanto, los } \\
\text { hongos y bacterias no están formados por células. (DE9). }\end{array}$ \\
\hline
\end{tabular}

Fuente: elaboración de las autoras.

Existen correlaciones entre algunas opciones de la evaluación formal (Tabla 1) y algunas opciones del cuestionario ad hoc (Tabla 3). Por lo tanto, al comparar los resultados obtenidos en ambas instancias, se ponen en evidencia las siguientes consideraciones.

1. Respecto de la estructura de las células

El 73\% de los estudiantes indicó correctamente en la Tabla 1 que Las células de muchos seres vivos tienen núcleo y se llaman eucariotas (opción b); sin embargo, en la Tabla 3, la opción (I): todas tienen núcleo fue la más elegida (73\%). Es decir, a pesar de la instrucción explícita, los niños no distinguieron claramente la diferencia entre células procariotas y eucariotas y generalizaron la presencia del núcleo. Esta elección estaría relacionada con la DE7. A esto se suma que un $40 \%$ de los estudiantes generalizó el efecto de los antibióticos a todas las células (opción e, Tabla 3). Esta respuesta estaría relacionada con la DE13 proveniente de una posible interpretación errónea del Texto 4 leído en clase.

Sobre la representación de una célula siempre rodeada por una membrana, si bien el $80 \%$ había elegido la opción e, de la Tabla 1, solamente el 53\% eligió la opción g, de la Tabla 3: siempre tienen una membrana que las rodea.

Por último, el $20 \%$ de los estudiantes señaló que todas las células tienen la misma forma (opción k, Tabla 3). Esto podría ser una consecuencia de las imágenes que utilizan los libros de texto escolar para representar las células y estaría relacionada con la DE1. Esta respuesta, sin embargo, no necesariamente implica que el $80 \%$ de los estudiantes logró identificar que la representación artística de la célula es una modelización sino que, posiblemente, se debe a que, en el material utilizado, se mostraron representaciones artísticas diferentes provenientes de diversos textos (por ejemplo, algunas células con "colitas", otras con "ramificaciones"). Esto estaría relacionado con las DE2, DE3 y DE4.

\section{Respecto de las células como mínimas unidades vitales}

El 93\% de los estudiantes indicó correctamente la opción c de la Tabla 1: Las células son la mínima unidad de la vida. Sin embargo, su significación parece no haber sido comprendida, ya que sólo un 33\% de los alumnos marcó la opción b de la Tabla 3: son lo más pequeño que 
existe con vida. Esta falla en la comprensión fue refrendada por el $67 \%$ de quienes eligieron la opción f, de la Tabla 3: pueden estar formadas por otras células, y por el 20\% que eligió la opción a: están vivas si tienen adentro otras células vivas. La falta de comprensión acerca del significado de "unidad vital" estaría relacionada con la DE5. Por otra parte, es importante recordar que a varios estudiantes, durante el diálogo con la docente, no les había resultado convincente la idea de que las células muertas siguieran siendo células (relato c). Esto se vio reflejado en el $13 \%$ de alumnos que eligieron la opción d de la Tabla 2: siempre están vivas y estaría relacionado con la DE6.

\section{Respecto de las células como constituyentes de los seres vivos}

El $87 \%$ de los estudiantes de $5^{\text {to }}$ grado respondieron correctamente en la evaluación formal que todos los seres vivos están formados por células (opción a, de la Tabla 1); sin embargo, solo el $27 \%$ eligió la opción i: forman parte de los animales y plantas y el mismo porcentaje eligió la opción j: pueden ser hongos, de la Tabla 3. Estos datos estarían indicando que habría fallado el aprendizaje modelizado que permite incluir a las células como "unidad constituyente" de todos seres vivos y estaría relacionado con la DE9.

Un 87\% que eligió correctamente la opción d, de la Tabla 1: los grupos de células que realizan una misma función forman un tejido; sin embargo, solo $60 \%$ eligió la opción $h$, de la Tabla 3: pueden formar los tejidos de un organismo. Esto también podría estar relacionado con la DE2 ya que, de acuerdo a las imágenes utilizadas durante la enseñanza, solamente algunas células (pero no todas) tendrían "prolongaciones" hacia afuera y se podrían "tocar" unas con otras.

La baja en los porcentajes de respuestas correctas que correlacionan entre la Tablas 1 y 3 serían evidencias de falencias en la construcción de significados dado que la docente presentó ambos instrumentos como instancias de la evaluación general de la temática y, por lo tanto, los alumnos los respondieron con el mismo nivel de compromiso.

\section{Análisis del desempeño individual}

A continuación, se explorará la consistencia interna de las respuestas de cada estudiante al cuestionario ad hoc, comparada con sus propias respuestas en la evaluación formal. Frente a las distintas posibilidades, sería posible la siguiente clasificación en relación a la construcción de contextos modelizadores para el aprendizaje del tema célula:

- Carencia de modelo. Dentro de esta categoría se ubicarían aquellos estudiantes que fueron inconsistentes en sus respuestas al comparar la evaluación y el cuestionario ad hoc o bien dentro del mismo cuestionario ad hoc para todas las categorías (modelo estructural, modelo funcional y modelo de la célula como constituyente de los seres vivos). Es decir, aquellos que, por ejemplo, señalaron correctamente que la célula es la mínima unidad de la vida en la evaluación formal pero no marcaron son lo más pequeño que existe con vida en el cuestionario ad hoc. Esta situación estaría revelando un aprendizaje memorístico repetitivo, sin un contexto modelizador de lo aprendido. Es el caso de los alumnos 2, 4, 5, 6, 8, 9, 12, 13 y 15 .

- Incipiente modelo estructural de la célula. Incluiría a aquellos estudiantes que respondieron de manera consistente y correcta a las opciones c, e, g, k, I del cuestionario ad hoc y su correlato en la evaluación formal de la docente. Ninguno de los 15 estudiantes se incluye en esta categoría. 
- Incipiente modelo funcional de la célula. Aquellos estudiantes que respondieron de manera consistente y correcta a las opciones $a, b, d, f$ del cuestionario ad hoc y su correlato en la evaluación formal de la docente en referencia a las células como mínimas unidades vitales. Es el caso del estudiante 3.

- Incipiente modelo de la célula como constituyente de los seres vivos. Aquellos estudiantes que respondieron de manera consistente y correcta a las opciones $\mathrm{h}, \mathrm{i}, \mathrm{j}$ del cuestionario ad hoc y su correlato en la evaluación formal de la docente. Es el caso de los estudiantes 1 y 11.

- Posibles modelos explicativos erróneos. En el caso de los estudiantes 1, 2, 5, 7, 8, 10, 11 y 14 se observa que han señalado simultáneamente las opciones c y / de la Tabla 3: Las células están vivas si tienen núcleo y Todas las células tienen núcleo. Esto podría tener sustento desde dos posibles modelos explicativos:

- un razonamiento del tipo todas las células siempre están vivas; todas las células tienen núcleo; entonces, las células están vivas si tienen núcleo; o bien,

- si se considera que hay células sin núcleo y las células vivas tienen núcleo; entonces, células procariotas o que no tienen núcleo no estarían vivas.

En ambos casos, el modelo sería científicamente incorrecto pero consistente en sí mismo (no podría originar un conflicto cognitivo per se). Dado que los estudiantes 2, 5 y 8 mostraron otro tipo de inconsistencias en sus respuestas, han sido clasificados como carentes de modelo. Pero los estudiantes identificados como 1, 7, 10, 11 y 14, mantuvieron consistencia en sus respuestas y, por lo tanto, pertenecen a esta categoría.

Es importante destacar que responder de manera consistente pero errónea, desde el punto de vista científico, podría ser evidencia de la gestación de un modelo mental que podría ser resistente a una subsiguiente instrucción. Este tipo de modelo mental ha sido clasificado como de tipo "puente" y podría constituirse en un obstáculo epistemológico de aprendizaje, tal como ya se ha observado para estudiantes novatos del nivel universitario (GAROFALO, 2010; GARÓFALO; GALAGOVSKY; ALONSO, 2015). Este podría ser el caso de los estudiantes mencionados. Para confirmarlo, sería necesario profundizar en la investigación y realizar, por ejemplo, entrevistas personalizadas.

En la Tabla 6 se indica la distribución de los estudiantes en función de la clasificación de sus respuestas. En ella se observa que ninguno de los 15 alumnos mostró evidencias de construcción de modelos consistentes en todas las categorías, un 60\% mostraron carencia de modelos y un $40 \%$ mostraron indicios de posibles modelos explicativos científicamente incorrectos. Los estudiantes 1, 2 y 11 mostraron posibles modelos explicativos erróneos para alguna categoría y, simultáneamente, incipientes modelos explicativos para otras.

Tabla 6 - Categorización de los posibles modelos explicativos de los estudiantes de $5^{\text {to }}$ grado a partir de sus respuestas en la evaluación formal y el cuestionario ad hoc

\begin{tabular}{|c|c|c|c|c|c|c|c|c|c|c|c|c|c|c|c|c|}
\hline Clasificación & 1 & 2 & 3 & 4 & 5 & 6 & 7 & 8 & 9 & 10 & 11 & 12 & 13 & 14 & 15 & $\%$ \\
\hline Carencia de modelo & & & & & & & & & & & & & & & & 60 \\
\hline Incipiente modelo estructural & & & & & & & & & & & & & & & & 0 \\
\hline Incipiente modelo funcional & & & & & & & & & & & & & & & & 7 \\
\hline $\begin{array}{l}\text { Incipiente modelo de la célula como } \\
\text { constituyente de los seres vivos }\end{array}$ & & & & & & & & & & & & & & & & 7 \\
\hline Posibles modelos explicativos erróneos & & & & & & & & & & & & & & & & 40 \\
\hline
\end{tabular}

Fuente: elaboración de las autoras. 


\section{Comparación entre respuestas de estudiantes de $5^{\text {to }}, 6^{\text {to }}$ y $7^{\text {mo }}$ grado}

\section{Análisis del desempeño grupal}

La Tabla 7 muestra el porcentaje de niños que seleccionaron cada ítem del cuestionario ad hoc, sobre un total de 15 estudiantes de $5^{\text {to }}$ (datos ya mostrados en la Tabla 3), 10 estudiantes de $6^{\text {to }}$ y 12 estudiantes de $7^{\text {mo }}$ grado. La suma de porcentajes supera el $100 \%$ porque los estudiantes podían seleccionar más de una opción. Cabe aclarar que, si bien célula no fue un tema enseñado por las docentes de $6^{\text {to }}$ y $7^{\text {mo }}$ grado, en los libros de texto siempre se retoma como introducción a los diferentes sistemas del cuerpo humano.

Tabla 7 - Respuestas de los alumnos de $5^{\text {to }}, 6^{\text {to }}$ y $7^{\text {mo }}$ grado al cuestionario ad hoc [en bastardilla se indican las respuestas correctas desde el punto de vista científico]

\begin{tabular}{|l|c|c|c|}
\hline \multirow{2}{*}{ Las células... } & \multicolumn{3}{|c|}{$\%$ de elección } \\
\cline { 2 - 4 } & $5^{\circ}$ & $6^{\circ}$ & $7^{\circ}$ \\
\hline (a) están vivas si tienen adentro otras células vivas.. & 20 & 10 & 8 \\
\hline (b) son lo más pequeño que existe con vida. & 33 & 30 & 42 \\
\hline (c) están vivas si tienen núcleo. & 67 & 60 & 67 \\
\hline (d) siempre están vivas. & 13 & 0 & 0 \\
\hline (e) son destruidas por medicamentos antibióticos. & 40 & 40 & 33 \\
\hline (f) pueden estar formadas por otras células. & 67 & 40 & 33 \\
\hline (g) siempre tienen uma membrana que las rodea. & 53 & 50 & 67 \\
\hline (h) pueden formar los tejidos de un organismo. & 60 & 60 & 50 \\
\hline (i) forman parte de los animales y plantas. & 27 & 20 & 33 \\
\hline (j) pueden ser hongos.. & 27 & 20 & 33 \\
\hline (k) todas tienen la misma forma. & 20 & 30 & 42 \\
\hline (l) todas tienen núcleo. & 73 & 80 & 83 \\
\hline
\end{tabular}

Fuente: elaboración de las autoras.

1. Respecto de la estructura de las células

Se observó un incremento en porcentajes de ideas erróneas para las opciones $k$ : todas tienen la misma forma, y l: todas tienen núcleo. Estos aumentos pondrían en evidencia un refuerzo en el aprendizaje consecutivo, posiblemente debido a la presencia de representaciones artísticas modelizadas similares en los diversos libros de texto (OSPINA QUINTERO; GALAGOVSKY, 2017). Estos resultados son consistentes con la literatura que señala que los estudiantes asocian la estructura de la célula al núcleo más que al citoplasma (MENGASCINI, 2017) y con los artículos que exponen creencias de los estudiantes acerca de que las células tienen, todas, la misma forma (BUITRAGO REINOSA, 2014; FLORES; TOVAR; GALLEGOS 2003; RODRÍGUEZ PALMERO, 2003; VERHOEFF, 2008).

Ospina Quintero y Galagovsky (2017) han señalado que las imágenes estandarizadas del modelo de célula llevan implícitas numerosas convenciones de escala, forma y color que, al no explicitarse, conducirían a la construcción de modelos científicamente incorrectos en los estudiantes. Así, a medida que transcurre su escolaridad, irían afianzando la idea de que todas las células tienen las mismas subestructuras, todas ellas con determinada y única forma y color, tal como se muestra en dichas representaciones. 


\section{Respecto de las células como mínimas unidades vitales}

Se verificó un descenso en los porcentajes de ideas erróneas mostradas en las opciones $a, d, f$. Esto evidenciaría una mayor comprensión de la significación del sintagma "mínima unidad vital" a medida que transcurre la escolaridad.

3. Respecto de las células como constituyentes de los seres vivos

Se observó un aumento en el porcentaje de la opción correcta $i$ forman parte de los animales y plantas, pero un aumento mucho menor para la opción j pueden ser hongos. Estos resultados son coherentes con distintas investigaciones que señalan que si bien alrededor del $10 \%$ de los estudiantes de secundario no considera a las plantas como seres vivos incluso después de la instrucción -, los porcentajes son mayores en el caso de bacterias y hongos (BANET; AYUSO, 2000).

Tal como se observa en la Tabla 7, la mayor parte de las ideas incluidas en las opciones $b, c, e, g, h, j$ se mantuvieron en porcentajes similares durante el transcurso del segundo ciclo. Este resultado estaría evidenciando que lo aprendido inicialmente a los 10-11 años sobre el tema célula, poco cambia hasta los 12-13 años y mostraría un posible sustento de las investigaciones que han demostrado errores conceptuales en estudiantes de escuela secundaria.

\section{Análisis del desempeño individual}

La Tabla 8 muestra los patrones de respuesta individuales de cada alumno de $6{ }^{\text {to }}$ (1625) y $7^{\text {mo }}$ grado (26-37).

Tabla 8 - Respuestas completas de los 10 alumnos de $6^{\text {to }}$ grado (\#16-25) y los 12 alumnos de $7^{\text {mo }}$ grado (\#26-37) al cuestionario ad hoc [las opciones correctas se señalan en bastardillas]

\begin{tabular}{|c|c|c|c|c|c|c|c|c|c|c|c|c|c|c|c|c|c|c|c|c|c|c|}
\hline Opción & 16 & 17 & 18 & 19 & 20 & 21 & 22 & 23 & 24 & 25 & 26 & 27 & 28 & 29 & 30 & 31 & 32 & 33 & 34 & 35 & 36 & 37 \\
\hline a & & & & & & & & & & & & & & & & & & & & & & \\
\hline $\boldsymbol{b}$ & & & & & & & & & & & & & & & & & & & & & & \\
\hline C & & & & & & & & & & & & & & & & & & & & & & \\
\hline$d$ & & & & & & & & & & & & & & & & & & & & & & \\
\hline e & & & & & & & & & & & & & & & & & & & & & & \\
\hline$f$ & & & & & & & & & & & & & & & & & & & & & & \\
\hline $\boldsymbol{g}$ & & & & & & & & & & & & & & & & & & & & & & \\
\hline $\boldsymbol{h}$ & & & & & & & & & & & & & & & & & & & & & & \\
\hline$i$ & & & & & & & & & & & & & & & & & & & & & & \\
\hline $\boldsymbol{j}$ & & & & & & & & & & & & & & & & & & & & & & \\
\hline k & & & & & & & & & & & & & & & & & & & & & & \\
\hline I & & & & & & & & & & & & & & & & & & & & & & \\
\hline
\end{tabular}

Fuente: elaboración de las autoras.

Pese a haber recibido enseñanza por parte de otras docentes y a partir de diferentes textos escolares, es posible observar, tanto en los alumnos de $6^{\text {to }}$ como $7{ }^{\mathrm{mo}}$ grado, que algunos patrones de respuesta correlacionan con los de $5^{\text {to }}$ grado e, incluso, se afianzan. Es el caso de los estudiantes que marcaron simultáneamente las opciones c y l: Las células están vivas si 
tienen núcleo y Todas las células tienen núcleo. Todos los estudiantes de $6^{\text {to }}$ grado que marcaron la opción c también marcaron la opción I (60\% del total) mientras que en $7^{\text {mo }}$ grado, lo hicieron todos los estudiantes menos uno (identificado como 26 ) siendo un $67 \%$ del total. En $5^{\text {to }}$ grado habían marcado en simultáneo ambas opciones un 53\% de los estudiantes.

Por otra parte, la inconsistencia de marcar en simultáneo las opciones b (son lo más pequeño que existe con vida) y $f$ (pueden estar formadas por otras células), que en el caso de $5^{\text {to }}$ grado había ocurrido en el $27 \%$ de los alumnos, no se observa en $6^{\text {to }}$ grado y solamente se da en un alumno de $7^{\text {mo }}$ grado (8\%).

En la Tabla 9 se categorizan los posibles modelos explicativos de los estudiantes de $6^{\text {to }}$ y $7^{\text {mo }}$ grado, tal como se hizo con los alumnos de $5^{\text {to }}$ grado. Es importante destacar que, en este caso, solamente se cuenta con la información obtenida del cuestionario ad hoc y, por lo tanto, la evidencia es más restringida. Por tal motivo, es factible que muchos de los alumnos que fueron clasificados con posibles modelos explicativos erróneos, al realizar una investigación más exhaustiva con entrevistas personales o nuevos instrumentos, muestren inconsistencias $y$, por lo tanto, carencia de modelo. Es destacable, de todas formas, que tanto en $6^{\text {to }}$ como en $7^{\text {mo }}$ grado parece haber un mayor porcentaje de alumnos con modelos incipientes de célula.

Tabla 9 - Categorización de los posibles modelos explicativos de los 10 alumnos de $6^{\text {to }}$ grado (\#16-25) y los 12 alumnos de $7^{\text {mo }}$ grado (\#26-37) a partir de sus respuestas al cuestionario ad hoc

\begin{tabular}{|c|c|c|c|c|c|c|c|c|c|c|c|c|c|c|c|c|c|c|c|c|c|c|c|c|}
\hline Clasificación & 16 & 17 & 18 & 19 & 20 & 21 & 22 & 23 & 24 & 25 & $\%$ & 26 & 27 & 28 & 29 & 30 & 31 & 32 & 33 & 34 & 35 & 36 & 37 & $\%$ \\
\hline $\begin{array}{l}\text { Carencia de mo- } \\
\text { delo }\end{array}$ & & & & & & & & & & & 10 & & & & & & & & & & & & & 17 \\
\hline $\begin{array}{l}\text { Incipiente mo- } \\
\text { delo estructural }\end{array}$ & & & & & & & & & & & 10 & & & & & & & & & & & & & 0 \\
\hline $\begin{array}{l}\text { Incipiente mo- } \\
\text { delo funcional }\end{array}$ & & & & & & & & & & & 20 & & & & & & & & & & & & & 33 \\
\hline $\begin{array}{l}\text { Incipiente mo- } \\
\text { delo consti- } \\
\text { tuyente seres } \\
\text { vivos }\end{array}$ & & & & & & & & & & & 10 & & & & & & & & & & & & & 17 \\
\hline $\begin{array}{l}\text { Posibles mode- } \\
\text { los explicativos } \\
\text { erróneos }\end{array}$ & & & & & & & & & & & 80 & & & & & & & & & & & & & 75 \\
\hline
\end{tabular}

Fuente: elaboración de las autoras.

\section{Conclusiones}

En este trabajo se han obtenido evidencias sobre dificultades para procesar información sobre el concepto de célula en estudiantes de $5^{\text {to }}, 6^{\text {to }}$ y $7^{\text {mo }}$ grado de escuela primaria.

Una comparación entre datos provenientes de la evaluación formal tomada por la maestra en $5^{\text {to }}$ grado y las respuestas a un cuestionario ad hoc en el que se indagaban posibles construcciones cognitivas erróneas de los niños (Tablas 1-2 y Tablas 3-4, respectivamente), hizo evidente que los términos "unidad" y "vital" tienen connotaciones biológicas de alto nivel de conceptualización, cuya reiterada repetición no asegura un aprendizaje sustentable del tema (GALAGOVSKY, 2004a, 2004b). 
Al analizar las respuestas de cada uno de los 15 estudiantes (Tablas 2 y 4), fue posible detectar algunas evidencias de construcción de modelos explicativos incipientes siendo destacable la aparición de modelos explicativos consistentes pero científicamente incorrectos (Tabla 6). Estos últimos, como ya se ha mencionado, podrían ser indicadores de un modelo mental de tipo "puente". La comparación entre las construcciones cognitivas realizadas por los niños de $5^{\text {to }}, 6^{\text {to }}$ y $7^{\text {mo }}$ grado (Tablas 7,8 y 9) pusieron de manifiesto que modelos erróneos detectados durante la formación del concepto célula podrían ser conservados y funcionarían como potenciales futuros obstáculos de aprendizaje. El presente trabajo revelaría, por lo tanto, que las ideas erróneas previas o posteriores a la instrucción publicadas en distintas investigaciones en alumnos de años más avanzados (BANET; AYUSO, 2000; BUITRAGO REINOSA, 2014; FLORES; TOVAR; GALLEGOS, 2003; LEGEY et al., 2012; MENGASCINI, 2005, 2017; RODRÍGUEZ PALMERO, 2000; RIEMEIER; GROPENGIEßER, 2008) podrían provenir de dificultades en el procesamiento de la información presentada a los estudiantes durante su escolaridad primaria.

En cuanto a las implicancias didácticas, si bien los resultados no son generalizables por el pequeño tamaño de la muestra, son indicios reveladores del cuidado que debería instalarse en la enseñanza inicial de temas que requieren una abstracción importante. La concepción de una enseñanza espiralada en complejidad (TAKAYA, 2008) no recomendaría iniciar el tema célula desde una definición que incluya significaciones unívocas de los términos mínima, unidad, estructural, funcional, vital acompañados de una única representación modélicosimbólica creada artísticamente. La historia misma del concepto de célula responde a una trayectoria de investigación que parte a mediados del siglo XIX desde la diversidad celular y sólo luego de 100 años se acepta la uniformidad y generalización informativa que supone un modelo (OSPINA QUINTERO; GALAGOVSKY, 2017).

Es fundamental que los docentes reflexionemos acerca de la importancia de construir contextos de significación adecuados desde el punto de vista científico para enmarcar los conceptos que enseñamos, en un esfuerzo de intercambio entre el discurso de la enseñanza y la capacidad de su procesamiento cognitivo y de otorgamiento de sentido por parte de los niños.

Por otra parte, es interesante reflexionar acerca de la importancia de detectar en los estudiantes la construcción de posibles modelos explicativos erróneos que podrían constituirse en futuros obstáculos epistemológicos de aprendizaje. Evidencias como las mostradas en este trabajo sobre cómo aprendizajes iniciales podrían originar futuras ideas previas erróneas debería cuestionar a funcionarios educativos y docentes, generadores y ejecutantes de currículos, respectivamente, sobre qué contenidos y con qué tratamiento didáctico resultarían apropiados para ser enseñados a cada edad. La toma de conciencia sobre el carácter modélico tanto de definiciones como de representaciones artísticas de la mayoría de los conceptos científicos enseñados son elementos indispensables para la reflexión didáctica que tienda a mejorar la enseñanza en la escuela primaria.

\section{Agradecimientos}

Las autoras agradecen los financiamientos: Agencia Nacional de Promoción Científica y Tecnológica y Universidad de Buenos Aires. 


\section{Referências}

ANGULO PINEDO, E. La imagen de la célula: evolución de la imagen de la célula en los textos científicos. Bio: revista del colegio oficial de biólogos, España, n. 18, p. 4-7, 1999.

ANGULO PINEDO, E. La imagen de la célula en los libros de texto de enseñanzas no universitarias. Bio: revista del colegio oficial de biólogos, España, n. 19, p. 2-4, 2000.

BANET, E.; AYUSO, G. E. Teaching genetics at secondary school: a strategy for teaching about the localitation of Inheritance information. Science Education, Hoboken, v. 84, n. 3, p. 313-351, 2000. DOI: http://doi.org/bgfq3m.

BARROW, L. H. Do elementary science methods textbooks facilitate the understanding of magnet concepts? Journal of Science Education and Technology, Switzerland, v. 9, n. 3, p.199-205, 2000. DOI: https://doi.org/10.1023/A:1009487432316.

BEKERMAN, D. G. La utilización de la imagen en los procesos de enseñanza y aprendizaje de química orgánica. 2007. 249 h. Tesis (Doctorado en Enseñanza de Química) - Universidad de Buenos Aires, Buenos Aires, 2007.

BEKERMAN, D.; GALAGOVSKY, L.R. El lenguaje gráfico de la química: una perspectiva para el análisis de errores. Enseñanza de las Ciencias, Barcelona, n. extra, p. 496-502, 2009.

BUITRAGO REINOSA, M. A. Enseñanza-aprendizaje del concepto de célula en estudiantes de básica secundaria. 2014. Tesis (Maestría en Enseñanza de las Ciencias Exactas y Naturales) - Universidad Nacional de Colombia, Manizales, 2014. Recuperado el 17 ago. 2020 de: http://www.bdigital.unal. edu.co/20425/1/8412009.2014.pdf.

CAMACHO GONZÁLES, J. P.; JARA COLICOY, N.; MORALES ORELLANA, C.; RUBIO GARCIA, N.; MUÑOS GUERRERO, T.; TIRADO, R. Los modelos explicativos del estudiantado acerca de la célula eucarionte animal. Revista Eureka sobre Enseñanza y Divulgación de las Ciencias, Cádiz, v. 9, n. 2, p. 196-212, 2012.

CARVALHO, G. S.; TRACANA, R. B.; SKUJIENE, G.; TURCINAVICIENE, J. Trends in environmental education images of textbooks from western and eastern european countries and non-european countries. International Journal of Science Education, London, v. 33, n. 18, p. 2587-2610, 2011. DOI: https://doi.org/10.1080/09500693.2011.556831.

EDELSZTEIN, V. C.; GALAGOVSKY, L. Simplificación de los textos escolares y sus posibles efectos en el aprendizaje: el caso de los sistemas del cuerpo humano en un $5^{\text {to }}$ grado. Revista de Educación en Biología, Buenos Aires, v. 20, n. 2, p. 41-55, 2017. Recuperado el 17 ago. 2020 de: https://revistas. unc.edu.ar/index.php/revistaadbia/article/view/22514.

FLORES, F.; TOVAR, M. E.; GALLEGOS, L. Representation of the cell and its processes in high school students: an integrated view. International Journal of Science Education, London, v. 25, n. 2, p. 269286, 2003. DOI: https://doi.org/10.1080/09500690210126793.

GALAGOVSKY, L. Del aprendizaje significativo al aprendizaje sustentable, parte 2: derivaciones comunicacionales y didácticas. Enseñanza de las Ciencias, Barcelona, v. 22, n. 3, p. 349-364, $2004 a$.

GALAGOVSKY, L. Del aprendizaje significativo al aprendizaje sustentable, parte 1: el modelo teórico. Enseñanza de las Ciencias, Barcelona, v. 22, n. 2, p. 230-240, 2004b.

GALAGOVSKY, L.; BEKERMAN, D. La química y sus lenguajes: un aporte para interpretar errores de los estudiantes. Revista Electrónica de Enseñanza de las Ciencias, Vigo, v. 8, n. 3, p. 952-975, 2009. 
GALAGOVSKY, L.; EDELSZTEIN, V. C. Obstáculos de aprendizaje en niños de 10-12 años sobre el tema sistema circulatorio humano: una propuesta teórica en base a evidencias. Ciência \& Educação, Bauru, v. 24, n. 2, p. 283-299, 2018. DOI: https://doi.org/10.1590/1516-731320180020003.

GALAGOVSKY, L.; DI GIACOMO M. A.; CASTELO, V. Modelos vs. dibujos: el caso de la enseñanza de fuerzas intermoleculares. Revista Electrónica de Enseñanza de las Ciencias, Vigo, v. 8, n. 1, p. 1-22, 2009.

GARCÍA BARROS, S.; MARTÍNEZ LOSADA, C. La nutrición en textos escolares del último ciclo de Primaria y primero de Secundaria. Enseñanza de las Ciencias, Barcelona, n. ext., p. 1-6, 2005.

GARÓFALO, S. J. Análisis de obstáculos en el aprendizaje de metabolismo de hidratos de carbono: un estudio transversal. 2010. Tesis (Doctoral) - Universidad de Buenos Aires, Buenos Aires, 2010.

GARÓFALO, S.; ALONSO, M.; GALAGOVSKY, L. Nueva propuesta teórica sobre obstáculos epistemológicos de aprendizaje: el caso del metabolismo de los carbohidratos Enseñanza de las Ciencias, Barcelona, v. 32, n. 3, p. 155-171, 2014.

GARÓFALO, S. J.; GALAGOVSKY, L. R.; ALONSO, M. Redes semánticas poblacionales: un instrumento metodológico para la investigación educativa. Ciência \& Educação, Bauru, v. 21, p. 361-375, 2015. DOI: https://doi.org/10.1590/1516-731320150020007.

JIMÉNEZ, J. D.; PERALES, J. La evidencia experimental a través de la imagen de los libros de texto de Física y Química. Revista Electrónica de Enseñanza de las Ciencias, Vigo, v. 1 n. 2, p. 114-129, 2002.

LEGEY. A. P.; CHAVES, R.; MÓL, A. C. A.; SPIEGEL, C. N.; BARBOSA, J. V.; COUTINHO, C. M. L. M. Avaliação de saberes sobre célula apresentados por alunos ingressantes em cursos superiores da área biomédica. Revista Electrónica de Enseñanza de las Ciencias, Vigo, v. 11, n. 1, p. 203-224, 2012.

LÓPEZ-MANJÓN, A.; POSTIGO, Y. Análisis de las imágenes del cuerpo humano en libros de texto españoles de primaria. Enseñanza de las Ciencias, Barcelona, v. 32, n. 3, p. 551-570, 2014.

LÓPEZ-MANJÓN, A.; POSTIGO, Y. Representations of the human circulatory system. Journal of Biological Education, Philadelphia, v. 43, n. 4, p. 159-163, 2009.

MACNAB, W.; HANSELL, M. H.; JOHNSTONE, A. H. Cognitive style and analytical ability and their relationship to competence in the biological sciences. Journal of Biological Education, Philadelphia, v. 25, n. 2, p. 135-139, 1991. DOI: https://doi.org/10.1080/00219266.1991.9655192.

MALDONADO GALDEANO, G.; ROSSETTO, M. Investigación-acción en el aula de ciencias: Evolución del conocimiento infantil sobre células. Enseñanza de las Ciencias, Barcelona, n. ext., p. 1746-1749, 2009. Recuperado el 17 ago. 2020 de: https://dialnet.unirioja.es/servlet/articulo?codigo=6905847.

MARTÍNEZ LOSADA, C.; GARCÍA BARROS, S. Las actividades de primaria y ESO incluidas en libros escolares: ¿qué objetivos persiguen? ¿qué procedimientos enseñan? Enseñanza de las Ciencias, Barcelona, v. 21, n. 2, p. 243-264, 2003.

MATUS, L.; BENARROCH, A.; PERALES, F.J. Las imágenes sobre enlace químico usadas en los libros de texto de educación secundaria: análisis desde los resultados de la investigación educativa. Enseñanza de las Ciencias, Barcelona, v. 26, n. 2, p. 153-176, 2008.

MENGASCINI, A. La enseñanza y el aprendizaje de los tejidos vegetales en el ámbito universitario. Revista Electrónica de Enseñanza de las Ciencias, Vigo, v. 4, n. 2, p. 1-17, 2005. 
MENGASCINI, A. Propuesta didáctica y dificultades para el aprendizaje de la organización celular. Revista Eureka sobre Enseñanza y Divulgación de las Ciencias, Vigo, v. 3, n. 3, p. 485-495, 2017.

OSPINA QUINTERO, N.; GALAGOVSKY, L. La célula modelizada: una reflexión necesaria en el ámbito de la enseñanza. Revista Química Viva, São Paulo, v. 16, n. 2, p. 41-63, 2017.

OTERO, M. R.; MOREIRA, M. A.; GRECA, I. M. El uso de imágenes de textos de física para la enseñanza secundaria y universitaria. Investigações em Ensino de Ciências, Porto Alegre, v. 7, n. 2, p. 127-154, 2002.

PERALES, F. J.; JIMÉNEZ, J. Las ilustraciones en la enseñanza-aprendizaje de las ciencias: análisis de libros de texto. Enseñanza de las Ciencias, Barcelona, v. 20, n. 3. p. 369-386, 2002.

PÉREZ CEBALLOS, J. P.; GALOTTI, A.; VARELA, C.; TALAVERA, J. A. El sonido en textos de educación secundaria obligatoria (E. S. O.). In: MARTÍNEZ LOSADA, C.; GARCÍA BARROS, S. (ed.). La didáctica de las ciencias: tendencias actuales. La Coruña: Universidade da Coruña, 1999. p. 605-614.

PÉREZ DE EULATE, L.; LLORENTE, E.; ANDRIEU, A. Las imágenes de digestión y excreción en los textos de primaria. Enseñanza de las Ciencias, Barcelona, v. 17, n. 2, p. 165-178, 1999.

RIEMEIER, T.; GROPENGIEßER, H. On the roots of difficulties in learning about cell division: process-based analysis of students' conceptual development in teaching experiments. International Journal of Science Education, London, v. 30, n. 7, p. 923-939, 2008. DOI: https://doi. org/10.1080/09500690701294716.

RODRIGUEZ PALMERO, M. L. La célula vista por el alumnado. Ciência \& Educação, Bauru, v. 9, n. 2, p. 229-246, 2003. DOI: https://doi.org/10.1590/S1516-73132003000200006.

RODRÍGUEZ PALMERO, M. L. R. Revisión bibliográfica relativa a la enseñanza de la biología y la investigación en el estudio de la célula. Investigações em Ensino de Ciências, Porto Alegre, v. 5, n. 3, p. 237-263, 2000.

TAKAYA, K. Jerome Bruner's theory of education: from early Bruner to later Bruner. Interchange, Switzerland, v. 39, n. 1, p. 1-19, 2008. DOI: https://doi.org/10.1007/s10780-008-9039-2.

VERHOEFF, R. P.; WAARLO, A. J.; BOERSMA, K. T. Systems modelling and the development of coherent understanding of cell biology. International Journal of Science Education, London, v. 30, n. 4, p. 543568, 2008. DOI: https://doi.org/10.1080/09500690701237780. 